\title{
Review of Stroke Thrombolytics
}

\author{
Andrew Bivard, ${ }^{\mathrm{a}}$ Longting Lin, ${ }^{\mathrm{b}}$ Mark W. Parsons ${ }^{\mathrm{b}}$ \\ ${ }^{2}$ Departments of Neurology and Medicine, University of Melbourne, Royal Melbourne Hospital, Melbourne, Victoria, Australia \\ ${ }^{b}$ Department of Neurology, John Hunter Hospital, Hunter Medical Research Institute, University of Newcastle, Newcastle, NSW, Australia
}

The cornerstone of acute ischemic stroke treatment relies on rapid clearance of an offending thrombus in the cerebrovascular system. There are various drugs and different methods of assessment to select patients more likely to respond to treatment. Current clinical guidelines recommend the administration of intravenous alteplase (following a brain noncontract CT to exclude hemorrhage) within 4.5 hours of stroke onset. Because of the short therapeutic time window, the risk of hemorrhage, and relatively limited efficacy of alteplase for large clot burden, research is ongoing to find more effective and safer reperfusion therapy, as well as focussing on refinement of patient selection for acute reperfusion treatment. Studies using advanced imaging (incorporating perfusion CT or diffusion/perfusion MRI) may allow us to use thrombolytics, or possibly endovascular therapy, in an extended time window. Recent clinical trials have suggested that Tenecteplase, used in conjunction with advanced imaging selection, resulted in more effective reperfusion than alteplase, which translated into increased clinical benefit. Studies using Desmoteplase have suggested its potential benefit in a sub-group of patients with large artery occlusion and salveageable tissue, in an extended time window. Other ways to improve acute reperfusion approaches are being actively explored, including endovascular therapy, and the enhancement of thrombolysis by ultrasound insonation of the clot (sono-thrombolysis).

Keywords Ischemic stroke; Thrombolysis; Stroke trials

\author{
Correspondence: Andrew Bivard \\ Department of Neurology, John Hunter \\ Hospital/Hunter Medical Research \\ Institute, University of Newcastle, level \\ 4 centre, Royal Melbourne Hospital, \\ Grattan st, Parkville 3051, Melbourne, \\ Vic, Australia \\ Tel: +61 390356789 \\ Fax: +61 390353107 \\ E-mail: Andrew.bivard@unimelb.edu.au
}

Received: April 9, 2013

Revised: May 9, 2013

Accepted: May 9, 2013

The authors have no financial conflicts of interest.

\section{Introduction}

Stroke is the leading cause of adult disability in the developed world. ${ }^{1,2}$ In ischemic stroke, a blood clot (thrombus) leads to an area of brain experiencing a significant drop in cerebral blood flow, which can ultimately result in death of this hypoperfused tissue. Collateral blood flow gives rise to the ischemic penumbra, which is defined as an area of hypoperfused tissue that is at risk of death (infarction) if hypoperfusion persists, and is separate from tissue that has already died (or programmed to die) soon after stroke onset (core). ${ }^{3}$ The concept of the ischemic penumbra led to the notion that opening an occluded blood vessel in order to re-establish blood flow to the ischemic area (reperfusion) would rescue the ischemic penumbra from death ${ }^{3,4}$
(Figure 1). Reperfusion can be achieved through the use of systemic thrombolytic drugs, although thrombolytic agents may theoretically be more effective if delivered directly into the clot (intra-arterial delivery) or if assisted with ultrasound insonation of the clot (sono-thrombolysis).

\section{Thrombus formation and fibrinolysis}

A thrombus can originate from several different causes, which may alter its susceptibility to thrombolytic drugs. The main causes of thrombus formation in ischemic stroke are atherosclerosis (in-situ thrombus or thromboembolic) or forming in the heart (cardioembolic). It was originally hypothesized that the source of thrombi had a large determining influence on clot 

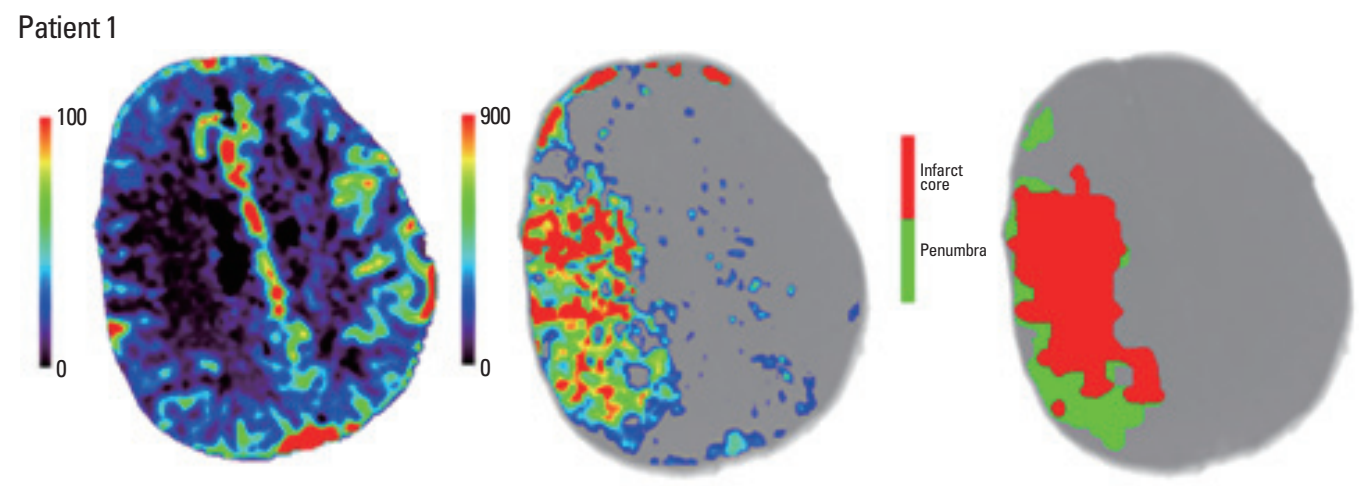

Patient 2
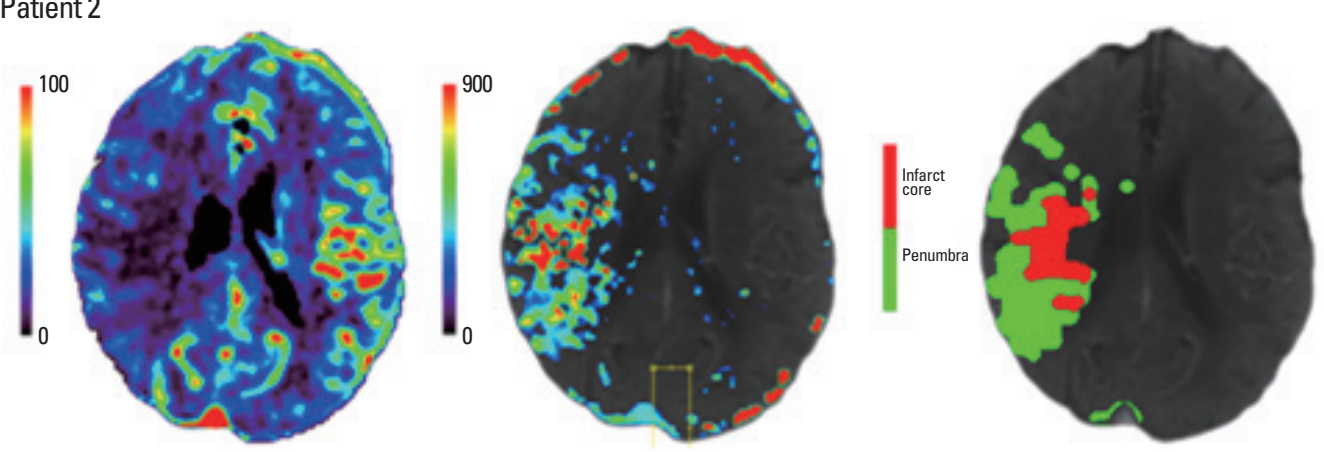

Figure 1. Clinical imaging of the (infarct) core and penumbra in two hyperacute stroke patients with proximal M1 middle cerebral artery territory occlusion. The right column shows the core (red) and penumbra (green) which are derived from the cerebral blood flow map (left column) and delay time map (middle column). The top patient one has a very large acute core (red) and very little penumbra (green). Their total core volume exceeded $70 \mathrm{~mL}$ and the patient had a poor outcome from thrombolysis - which was entirely predictable due to the large core. This illustrates the concept of 'futile reperfusion' where reperfusion will not help the patient and possibly it may even harm them. Patient two on the bottom row has a very large acute penumbra (green) and small core (red) and clearly will benefit substantially from thrombolysis (should it be effective at opening the vessel).

composition and therefore potentially upon susceptibility to thrombolytic treatment as thromboembolic clots tend to be platelet and fibrin rich and were formed in high flow areas (often referred to white clots), whilst cardioembolic can contain tissue debris such as fat, air or bacteria interwoven inside the platelet and fibrin mesh which were formed in low flow areas (often referred to as red clots). ${ }^{5,6}$ However recent histological studies analyzing the thrombi extracted from patients using intra-arterial clot retrieval showed thrombi composition was similar between cardiac and arterial origins. ${ }^{7}$

Atherosclerotic plaque rupture or cardio-embolic thrombosis (typically due to atrial fibrillation) leads to activation of the coagulation cascade as well as platelet activation. In the cascade, zymogens (free floating inactive coagulation factor precursors) are converted to an activated coagulation factor by interaction with the atherosclerotic plaque/thrombus. ${ }^{8}$ Each active zymogene is able to activate nearby zymogens, leading to a large localized reaction of coagulation factors. Activated platelets then catalyze an interaction between activated coagulation factors (zymogens) to aid in the generation of thrombin by conversion of the soluble protein fibrinogen to insoluble fibrin, forming a blood clot. There are two blood coagulation cascades (intrinsic and extrinsic pathways), that have separate initial pathways but converge on a common pathway ${ }^{9}$ (Figure 2). ${ }^{10}$

\section{Thrombolytic drugs}

Thrombolytic drugs dissolve (lyse) thrombi in the vascular bed by activating plasminogen to form plasmin. Plasmin is a proteolytic enzyme that breaks the crosslinks between fibrin molecules to destabilise the structural integrity of blood clots. The main types of thrombolytic drugs used in ischemic stroke to activate plasminogen are urokinase/streptokinase and tissue plasminogen activators (eg, Alteplase). Thrombolytic drug development has undergone at least three generations with the aim of enhancing fibrin specificity or reducing inhibition of thrombolysis by plasminogen activator inhibitor type 1 (Table 1 ).

Tissue Plasminogen activator (tPA) is a serine protease found on the endothelial cells lining blood vessels and is involved in the breakdown of blood clots (thrombus). A thrombus is composed of fibrin monomers that are cross-linked through lysine side chains which tPA binds too. Lysine binding of tPA results in a activation of plasminogen only around a thrombus, which minimises activation of circulating plasminogen. The lysine side 


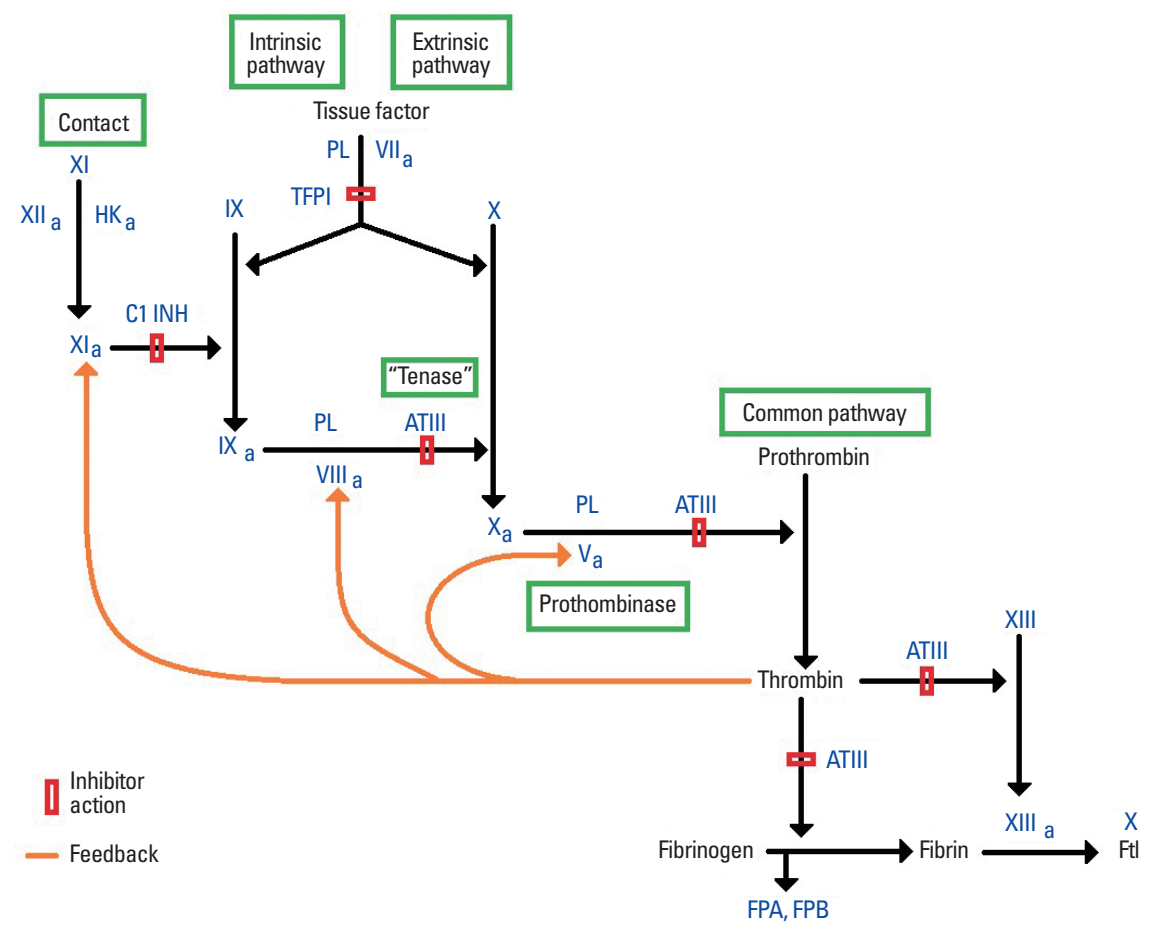

Figure 2. The coagulation process. The intrinsic pathway involves activation of components from within the vasculature (activation of Factor IX by Factor IXa). The extrinsic pathway is the principal initiating pathway for in vivo blood coagulation. The pathway involves the exposure of Tissue Factor (TF), a glycoprotein, and phospholipids to blood, these components are from the surface membranes of fibroblasts that are within and around blood vessels. TF and phospholipids, when exposed to blood, interact with Factor VIla to convert Factor IX to Factor IXa (from the intrinsic system). Factori VIIla is then formed from interactions between Factor IX and phospholipids. Factor VIIla and Factor X then combine to form Factor Xa. Factor Xa then interacts with phospholipids to form Factor Va and a "prothombinase". This is the stage where the intrinsic and extrinsic pathways converge and form the common pathway. Prothombinase the uses feedback mechanism for Factor VIlla and Factor Xla as a check to ensure that coagulation is still required, and if so, forms a thrombin. Thrombolytic drugs have action of factor XIII to break the fibrin crosslinks. ${ }^{55}$

Table 1. A comparison of the current thrombolytic drugs that are available in term of plasma half life, fibrin specificity and susceptibility to inhibition ${ }^{57}$

\begin{tabular}{lccc}
\hline Agent & Half-life (min & Fibrin selectivity & PAl-1 inhibition \\
\hline Urokinase & 15 & - & ++ \\
Alteplase & $4-8$ & ++ & +++ \\
Staphylokinase & 6 & -- & - \\
Monteplase & 23 & ++- & +++ \\
Pamiteplase & $30-47$ & ++ & +++ \\
Lanoteplase & $23-37$ & + & - \\
Reteplase & $14-18$ & + & ++ \\
Tenecteplase & $11-20$ & +++ & - \\
Desmoteplase & 138 & +++++ & $?$ \\
\hline
\end{tabular}

chains have a high affinity for binding with plasminogen, making the thrombus plasminogen rich. The tPA enzyme binds to fibrin components of a thrombus and catalyses plasminogen conversion to plasmin by cleavage of the arginine-valine bond at positions 560 and 561 to break down a clot by degrading the fibrin matrix of a thrombus. Plasmin then breaks the thrombus down into fibrin degradation products due to the plasmin's protease action in dissolving the thrombus. ${ }^{11}$ However, on fibrin bound plasmin, the inhibitory effect of alpha 2-antiplasmin and type 1 plasminogen activeator inhibitor restricts lysine binding. ${ }^{12}$
Streptokinase is a first generation thrombolytic agent. Streptokinase is an antigenic compound isolated and derived from purified streptococci bacteria. Therefore streptokinase is not a protease but binds to plasminogen for the generation of plasmin and is not restricted at the site of thrombus formation. Because of its non lysine specificity, Streptokinase, produces more fibrin degradation products (fibrinogensis) as a result of widespread lytic action in the body. Fibrinogensis occurs when there are high levels of fibrin in the blood and can cause thrombosis, haemorrhage or tissue oedema. Although much less expensive, this makes Streptokinase a less attractive agent for acute treatments in ischemic stroke than tPA products. Studies of streptokinase in acute stroke were stopped due to an increase in mortality compared to placebo due to increased haemorrhage rates. ${ }^{13,14}$ The specificity of tPA drugs (Alteplase, Retaplase, Tenecteplase and desmoteplase) for plasminogen bound fibrin means that conversion of plasminogen to plasma occurs in clots with minimal circulating plasma.

Urokinase is formed by kidneys and is found in urine. Like Streptokinase, Urokinase has limited clinical use due to its fibrinogensis. The 1999 Prolyse in Acute Cerebral Thromboembolism II trial (PROACT II) tested the benefit of intra arterial 


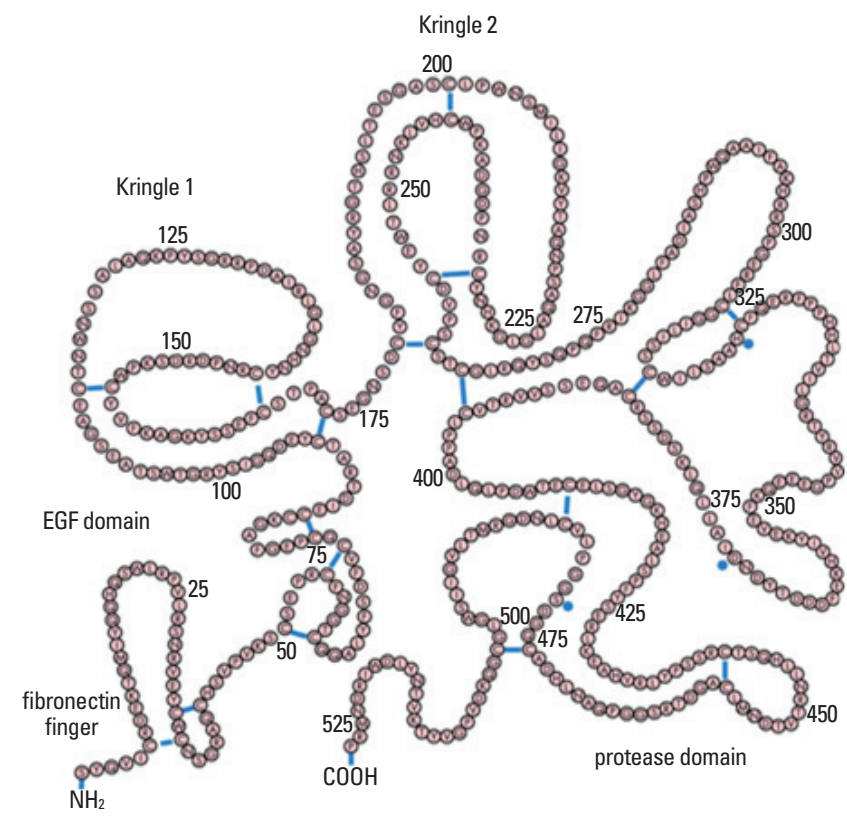

Figure 3. The molecular structure of alteplase. ${ }^{56}$

delivery of $9 \mathrm{mg}$ of recombinant prourokinasea (r-proUK) in 180 patients. Despite an increased rate of symptomatic intracranial haemorrhage the study found a significant benefit in patients treated with r-proUK at 90 days. ${ }^{15}$ To date, the PROACT II study is the only positive phase III intra-arterial trial. Some centres use r-proUK intravenously due to its low cost compared to other thrombolytic drugs.

The second generation thrombolytic drug Alteplase, is a recombinant form of human rtPA and has undergone the most study in the clinical stroke setting. Recombinant techniques mean that molecular cloning is used to bring genetic material together from multiple sources that would not otherwise be found together, to create new DNA sequences, which can be used to manufacture drugs. Alteplase is a purified glycoprotein (a protein with sugar chains covalently attached to polypeptide side chains) of 527 amino acids that is synthesised from the complementary DNA (cDNA) of natural human tissue-type plasminogen activator found in human melanoma cells and is made up of five structural components : a protease, epidermal growth factor (EGF) and two kringle domains (Figure 3). The lysine binding sites of alteplase are on the kringle 2 domain and are why alteplase has a high binding affinity to thrombi. In terms of pharmacodynamics, rtPA has a short half life of around 5 $\mathrm{min}$, and therefore requires an infusion after a bolus injection in the acute ischemic stroke setting.

The majority of ischemic stroke clinical research has revolved around alteplase, as it is the only Food and Drug Administration (FDA) approved drug for ischemic stroke. FDA approval for
Alteplase was licensed for the management of acute myocardial infarction in 1987, acute massive pulmonary embolism in 1990 and acute ischemic stroke in $1996 .{ }^{16}$ The total dose of Alteplase for acute ischemic stroke is divided into a $10 \%$ bolus and $90 \%$ as an infusion over $60 \mathrm{~min}$. Small dose-range studies for Alteplase in human stroke found increasing neurological benefit up to a dose of $0.85 \mathrm{mg} / \mathrm{kg}$, but an increased rate of haemorrhage with a dose of $0.95 \mathrm{mg} / \mathrm{kg} .{ }^{17}$ The ground-breaking NINDS-rtPA study was the first positive phase III acute stroke trial. This trial showed that early treatment (within 3 hours) of an ischemic stroke with alteplase substantially improved clinical outcomes. An Alteplase dose of $0.9 \mathrm{mg} / \mathrm{kg}$ was used in the NINDS trial. ${ }^{18}$ and found no significant increase in the risk of haemorrhage. ${ }^{19}$ The ideal dose of alteplase is still under debate with the original alteplase dose-ranging studies being quite small. It is felt that Asian people may be more prone to haemorrhage from $\mathrm{tPA}$, although this is not based on level one evidence. To this point, the standard dose of alteplase in Japan in $0.6 \mathrm{mg} / \mathrm{kg}$ based on a single Japanese study. ${ }^{20}$ On the other hand, there is justifiable concern that a reduced dose of alteplase will not successfully lyse larger clots, typically in more proximal locations. It has been reliably demonstrated that long clots on non contrast computed tomography (NCCT) show a reduced rate of reperfusion and subsequent clinical improvement. ${ }^{21}$ Indeed, a recent study of 130 patients using non-contrast $\mathrm{CT}$ to measure occlusion length identified that the tPA dose was independently predicative of thrombus resolution, with complete resolution in only $8 \%$ of patients. The average occlusion reduced by $20 \%$, while $15 \%$ of patients had an increase in clot length following tPA administration. Therefore tPA dose was associated with thrombus resolution and improved clinical outcome. ${ }^{22}$

Following the NINDS study, which showed that early treatment (within 3 hours) was the key to improving ischemic stroke outcome, there have been several studies investigating extending this treatment time window. The European Cooperative Acute Stroke Study (ECASS) I and II looked at administering alteplase between 0 and 6 hours after ischemic stroke onset and did not find an overall benefit, with an increased rate of haemorrhage in ECASS I. However ECASS I and II did not use advanced imaging and may have had a high rate of patients with very little penumbra to salvage, especially in the 3-6 hours time window. ECASS III subsequently demonstrated evidence of good outcome following treatment with $0.9 \mathrm{mg} / \mathrm{kg}$ Alteplase between 3 and 4.5 hours in patients < 80 years after symptom onset using only NCCT to exclude patients with haemorrhage or oedema. As a result of ECASS III, many countries have amended the license for stroke treatment with rtPA to 4.5 hours following NCCT assessment. 
There has been much interest in using advanced imaging to visualise the volume of the penumbra and infarct core, particularly with a view to extending the treatment window for thrombolysis. The EchoPlanar Imaging Thrombolytic Evaluation Trial (EPITHET) randomised ischemic stroke patients 3-6 hours after symptom onset to alteplase or placebo and used acute magnetic resonance imaging (MRI) to define the core and penumbra ('diffusion-perfusion mismatch'). The primary hypothesis of this phase II trial was that patients with perfusion-diffusion mismatch would have less infarct growth with alteplase than with placebo. Although the primary outcome was negative (mean geometric infarct growth) all secondary outcomes were positive and confirmed that alteplase attenuated infarct growth in mismatch patients. Other analyses from the EPITHET dataset have shown that the diffusion infarct core is the strongest predictor of response to thrombolysis, with a chance of good outcome dropping if the core $>25 \mathrm{~mL}$ and there being virtually no benefit $>70 \mathrm{~mL} .^{23,24}$ Pooled analysis from EPITHET and another trial of alteplase 3-6 hours after ischemic stroke, the Diffusion and Perfusion Imaging Evaluation for Understanding Stroke Evolution Study (DEFUSE), showed that patients in the 3-6 hours time window with a favourable imaging profile, i.e. a large penumbra, and small infarct core. ${ }^{25}$

As stroke occurs predominantly in the aged population, with $>45 \%$ of patients receiving Alteplase being over 70 years old, ${ }^{26}$ there is a concern about decreasing benefit from thrombolysis with age. The main concerns are over the possibility of aged related renal and hepatic impairments affecting the metabolising and clearance of alteplase as well as the possibility of an increased risk of haemorrhagic transformation of the infarct following $\mathrm{Al}$ teplase administration. There is also concern that the elderly tend to have subtle pre-morbid cognitive dysfunction and also may have less capacity for brain plasticity and recovery after stroke. However, the International stroke trial 3 (IST3), recently found there was no direct association between Alteplase administration and haemorrhage rate in elderly patients selected for alteplase treatment using NCCT imaging. ${ }^{27}$ This was the largest stroke thrombolytic trial ever, and randomised 0-6 hours patients to $0.9 \mathrm{mg} / \mathrm{kg}$ alteplase or placebo (without using advanced imaging selection). Although the primary outcome was negative, IST3 confirmed that patients treated within 3 hours of symptom onset clearly benefited from alteplase, and the elderly had as much benefit as did younger patients.

Tenecteplase (TNK-tPA) is a third generation point mutation tissue plasminogen activator created by recombinant DNA technology from a mammalian cell line. Like Alterphase, Tenecteplase is a 527 amino acid glycoprotein. Tenecteplase has modifications at three sites of the protein structure on the com- plementary DNA template that differentiate TNK from Alterphase, such as substitution of threonine 103 with asparagine, and a substitution of asparagine 117 with glutamine, both within the kringle 1 domain, and a tetra-alanine substitution at amino acids 296-299 in the protease domain (Figure 4). These structural and functional changes to the cDNA mean that Tenecteplase has a longer half life and greater binding affinity for fibrin and better resistance to inactivation by endogenous inhibitor (PAI-1) compared to Alteplase. The amino acids that were replaced at the three positions are called $\mathrm{T}, \mathrm{N}$, and $\mathrm{K}$ according to the one letter code for amino acids, giving the drug the name TNK. Tenecteplase is expressed with carbohydrate side chains linked to the glycosylation sites of the polypeptide. The carbohydrate side chains enlarge the molecule, reducing its elimination and prolonging its plasma half life. Tenecteplase can be administered by IV bolus, without the need for follow-up infusion, with a half life of 17 minutes. Tenecteplase has been approved for acute myocardial infarction, and was demonstrated to be superior to Alteplase. ${ }^{28,29}$

In ischemic stroke, the tenecteplase dose used for myocardial infarction $(0.5 \mathrm{mg} / \mathrm{kg})$ initially did not show benefit when using standard clinical criteria to select patients for treatment, with an increase in symptomatic haemorrhage. ${ }^{30}$ However when patients were selected for treatment based on acute computed tomography perfusion imaging to identify the volume of the infarct core and penumbra within 3-6 hours of symptom onset, treatment with tenecteplase at low dose $(0.1 \mathrm{mg} / \mathrm{kg})$ appeared to be superior to alteplase in a non-randomised study. ${ }^{31} \mathrm{~A}$ subsequent randomised phase IIb study using multimodal CT to

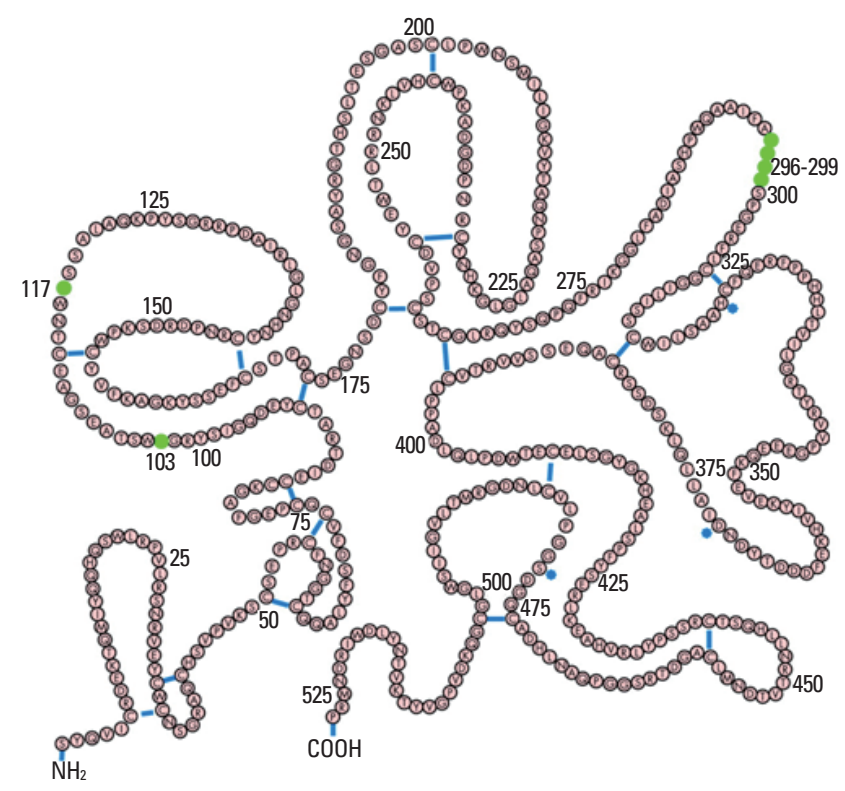

Figure 4. Molecular structure of tenecteplase. 
select patients (vessel occlusion, small core, large penumbra) found that moderate $(0.25 \mathrm{mg} / \mathrm{kg})$ and low $(0.1 \mathrm{mg} / \mathrm{kg})$ doses did lead to significantly better patient outcomes than standard dose Alteplase $(0.9 \mathrm{mg} / \mathrm{kg})$. Tenecteplase was associated with significantly increased reperfusion, early neurological improvement and improved 3 month functional outcome $\mathrm{e}^{32}$ with a strong dose-dependent relationship, with a $0.25 \mathrm{mg} / \mathrm{kg}$ dose achieving significant reperfusion and neurological improvement compared to $0.1 \mathrm{mg} / \mathrm{kg}$. Furthermore, despite the enhanced efficacy of tenecteplase for the larger proximal clots, there was not an increase in $\mathrm{ICH}$ (in fact a trend towards lower rates).

Desmoteplase is extracted from the saliva of vampire bats (desmodus rotundus). It was noted in 1932 that vampire bat saliva interfered with the haemostatic mechanisms of the host. ${ }^{33}$ The DNA sequencing of four plasminogen activators in vampire bat saliva were completed in 1991, with activator alpha 1 (rDSPA 1 , desmoteplase) being the most active $\mathrm{e}^{34}$ and shows a $72 \%$ homology to human t-PA. ${ }^{35}$ Desmoteplase is structurally similar to Alteplase, but is missing the plasmin sensitive cleavage site and lysine binding kringle 2 domain. This results in Desmoteplase being more selective for fibrin ( $2 \times$ increase in catalytic activity), and having no known effect on the blood brain barrier. Desmoteplase has a half life of 4 hours (compared to Alteplase 5 minutes, Reteplase 13 minutes, Tenecteplase 17 minutes).

A small phase three trial of Desmoteplase in Acute Ischemic Stroke (DIAS 2) has been completed and but demonstrated no benefit in patients selected for treatment biased on acute advanced neuroimaging findings. ${ }^{17,36}$ The trial randomised patients to desmoteplase or placebo 3-9 hours after stroke onset using imaging selection with CT perfusion or MRI, assessed visually for mismatch between core and penumbra volume of $>20 \%$ by the local investigator. This patient selection paradigm followed the promising phase 2 studies, DIAS and DEDAS, which demonstrated increased reperfusion and strong trends to improved outcome with desmoteplase compared to placebo. However, the primary clinical outcome DIAS 2 was negative. Apart from a very small sample size for a phase III study, it is thought the predominant reason for lack of benefit seen with desmoteplase was the lack of standardisation of the advanced imaging assessment. Additionally, DIAS 2 did not have a minimum or maximum volume of infarct or penumbra volume as inclusion criteria, as such, many patients had small perfusion lesions with a favourable natural history that would have made detecting a difference with desmoteplase treatment challenging even with a larger sample size. Subsequent analyses of pooled data from DIAS and DIAS-2 identified that patients with a proximal cerebral vessel occlusion or high grade stenosis had much greater mismatch tissue volumes and a positive response to desmoteplase compared to placebo. ${ }^{37}$

\section{Enhancing thrombolysis delivery}

The effectiveness of tPA treatment decreases the more proximal an occlusion becomes. The rate of early (effective) recanalization using alteplase is $25 \%$ in patients with a proximal middle cerebral artery occlusion and $10 \%$ in patients with an internal carotid occlusion. ${ }^{38}$ Additionally, the rate of re-occlusion, a situation where a thrombus moves down a vascular tree but does not dissolve and re-occludes a distal blood vessel, is as high as $30 \%$ with alteplase. ${ }^{39}$ Therefore, methods to enhance recanalization are required.

Intra Arterial (IA) thrombolysis and more recently clot retrieval have become increasingly popular acute stroke treatments, albeit without strong evidence. The PROACT II trial was the first IA thrombolysis trial to show benefit (compared to placebo). Subsequent phase II trials such as Interventional Management of Stroke (IMS) I and II suggested benefit of a 'bridging' IV/IA approach when compared to IV rtPA alone. With evolution of technology, there has been an increased interest in mechanically removing clots. ${ }^{40}$ However, three recent IA clot retrieval tials using first generation endovascular devices have recently been published including, IMS III, SYNTHESIS and MR RESCUE, all failed to show benefit compared to IV rtPA. This mostly likely relates to delays in revascularisation compared to IV treatment, and also to poor patient selection. For example, MR RESCUE not only had a very late time to endovascular treatment (median $>6$ hours), but the pre-treatment baseline infarct core volume was exceptionally large (median 60 $\mathrm{mL}){ }^{41,42}$ These trials with the first generation clot retrieval devices (MERCI and Penumbra) had quite poor recanalization rates, which may be another reason why they failed to show improved clinical outcomes compared to IV tPA alone. However, there is unbridled enthusiasm for the newer 'thrombectomy' devices such as Solitaire ${ }^{43}$ and Trevo, ${ }^{44}$ with phase II studies showing much better recanalization than with the first generation devices. However, it is unlikely any device will prove superiority to IV tPA unless clot retrieval can occur at a similar time point to IV treatment. However there is still a trend towards increased haemorrhage in patients undergoing IA treatments regardless of time to treatment.

Sono enhanced thrombolysis has been shown in vitro and in vivo to accelerate the enzymatic activity of thrombolysis. ${ }^{45}$ One proposed method of action, is that ultrasound pops the microbubbles in a targeted blood vessel to generate micro-streaming of blood to the occlusion as a delivery mechanism for tPA. Additionally, ultrasound causes enlargement of the fibrin mesh to allow better binding and penetration of tPA into a thrombus. ${ }^{46}$ 
Phase 2 clinical trials have shown that continuous transcranial ultrasound at $2 \mathrm{MHz}$ significantly increased the rate of early recanalisation in patients treated with alteplase. ${ }^{47}$ However these studies did not use the gold standard of angiography to assess recanalisation, rather they relied on transcranial ultrasound changes, which are less well validated. A phase III trial of sonolysis (CLOTBUSTER) is soon to commence. There has also been interest in administering intravenous micro-bubbles as a contrast agent in order to increase the available volume of micro-bubbles for ultrasound to affect, however this approach may increase risk of $\mathrm{ICH}{ }^{48}$

Glycoprotein IIb/IIIa inhibitors may prevent platelet activation induced by thrombolysis and promote a more complete and rapid action of thrombus breakup. ${ }^{49}$ Glycoprotein inhibitors are used to prevent platelet activation to stop new blood clots forming to avoid re-occlusion. Platelet activation by Adenosine diphosphate (ADP, stored in blood platelets and is released on platelet activation which can be blocked by clopidogrel) leads to a conformational change in platelet gpIIb/IIIa receptors that induces binding to fibrinogen. However recent myocardial studies have shown that gpIIb/IIIa inhibitors lead to more effective reperfusion, but also increased the rate of intracranial haemorrhage. ${ }^{50}$ For ischemic stroke there is currently little clinical data, with only small case series indicating a low rate of symptomatic intracranial haemorrhage after duel alteplase and gpIIb/IIIa administration. ${ }^{51,52}$

Nanotherapeutics aim to increase tPA delivery to the vessel occlusion. The current concept of thrombolysis is to inject a thrombus dissolving drug into the blood stream and hope that it reaches the occlusion site in a high enough concentration to totally dissolve the thrombus. The chosen doses of clot-lysing drugs that can be administered are a trade off between the potential risk of bleeding and the required dosage to have an effect. However, the more distal an occlusion is, the less likely there is to be effective drug delivery regardless of dose. One recent approach to guide tPA delivery is through the use of shear-activated nanotherapeutics (SA-NTs). ${ }^{53}$ However nanoparticles are only in phase one clinical trials.

Treatment of ischemic stroke with thrombolysis is a trade off between the risk of haemorrhage and the possible benefit. Clinical trials have shown that treatment with tPA in selected patients results in highly clinically significant improvement. However the criteria on how we best identify these highly treatmentresponsive patients are still undergoing investigation. There is much interest in the use of neuroimaging to enhance our ability to identify these responders but this approach is yet to be proven in a phase III clinical trial. ${ }^{54}$ While better thrombolytics and drug delivery mechanisms such as sono-thrombolysis may in- crease the breakdown of a thrombus, there is still the major risk of haemorrhage brought about by damaged to the blood brain barrier by the stroke. It is unknown if a resulting haemorrhage is caused by interactions of thrombolytic drugs and the blood brain barrier, or extensive brain damage brought on by an established infarct. Therefore it is unknown if better drugs or mechanisms will reduce the risk of haemorrhage after stroke, or if appropriately selecting patients with a large penumbra and without a large core using imaging reduces the rate of post lysis haemorrhage. The recent failure of the endovascular trials to show benefit compared to IV alteplase demonstrate that we should focus on early treatment with lytics and concentrate on either enhancing their delivery, and/or on better agents such as tenecteplase.

\section{References}

1. Senes S. How we manage stroke in Australia. AIHW cat no CVD 31. Canberra: Australian Institute of Health and Welfare, 2006.

2. Rothwell PM. The high cost of not funding stroke research: a comparison with heart disease and cancer. Lancet 2001;357: 1612-1616.

3. Baron, JC, Bousser MG, Rey A, Guillard A, Comar D, Castaigne P. Reversal of focal 'misery-perfusion syndrome' by extra-intracranial arterial bypass in hemodynamic cerebral ischemia: a case study with 150 positron emission tomography. Stroke 1981;12:454-459.

4. Stoll G, Bendszus M. Inflammation and atherosclerosis: novel insights into plaque formation and destabilization. Stroke 2006;37:1923-1932.

5. Friedman M, Bovenkamp GJV. The pathogenesis of a coronary thrombus. Am J Pathol 1966;48:19-44.

6. Jorgensen L. Experimental platelet and coagulation thrombi: a histological study of arterial and venous thrombi of varying age in untreated and heparinized rabbits. APMIS 1964;62:189223.

7. Marder VJ, Chute DJ, Starkman S, Abolian AM, Kidwell C, Liebeskind D, et al. Analysis of thrombi retrieved from cerebral arteries of patients with acute ischemic stroke. Stroke 2006;37: 2086-2093.

8. Hirsh J, Fuster V. Guide to anticoagulant therapy. Part 2: Oral anticoagulants. American Heart Association. Circulation 1994; 89:1469-1480.

9. Colman RW, Rao AK, Rubin RN. Factor XI deficiency and hemostasis. Am J Hematol 1994;47:73-8.

10. Hughes M, Lip GY. Stroke and thrombembolism in atrial fibrillation: a systemic review of stroke risk factors, risk stratification schema and cost effectiveness data. Thromb Haemost 
2008;99:295-304.

11. Brenner S. The molecular evolution of genes and proteins: a tale of two serines. Nature 1988;334:528-530.

12. Murray V, Norrving B, Sandercock PA, Terént A, Wardlaw JM, Wester P. The molecular basis of thrombolysis and its clinical application in stroke. J Intern Med 2010;267:191-208.

13. Donnan GA, Davis SM, Chambers BR, Gates PC, Hankey GJ, McNeil JJ, et al. Streptokinase for acute ischemic stroke with relationship to time of administration. JAMA 1996;276:961966.

14. The multicenter acute stroke trial - Europe study group. Thrombolytic therapy with streptokinase in acute ischemic stroke. $\mathrm{N}$ Engl J Med 1996;335(3):145-150.

15. Furlan A, Higashida R, Wechsler L, Gent M, Rowley H, Kase $\mathrm{C}$, et al. Intra-arterial prourokinase for acute ischemic stroke The PROACT II Study: A Randomized Controlled Trial. JAMA 1999;282:2003-2011.

16. Furlan AJ, Eyding D, Albers GW, Al-Rawi Y, Lees KR, Rowley $\mathrm{HA}$, et al. Dose Escalation of Desmoteplase for Acute Ischemic Stroke (DEDAS): evidence of safety and efficacy 3 to 9 hours after stroke onset. Stroke 2006;37:1227-1231.

17. Haley EC Jr, Levy DE, Brott TG, Sheppard GL, Wong MC, Kongable GL, et al. Urgent therapy for stroke. Part II. Pilot study of tissue plasminogen activator administered 91-180 minutes from onset. Stroke 1992;23:641-645.

18. The National Institute of Neurological Disorders and Stroke rtPA Stroke Study Group. Tissue plasminogen activator for acute ischemic stroke. N Engl J Med 1995;333:1581-1587.

19. Brott TG, Haley EC Jr, Levy DE, Barsan W, Broderick J, Sheppard GL, et al. Urgent therapy for stroke. Part I. Pilot study of tissue plasminogen activator administered within 90 minutes. Stroke 1992;23:632-640.

20. Yamaguchi T, Mori E, Minematsu K, Nakagawara J, Hashi K, Saito I, et al. Alteplase at $0.6 \mathrm{mg} / \mathrm{kg}$ for acute ischemic stroke within 3 hours of onset: Japan Alteplase Clinical Trial (J-ACT). Stroke 2006;37:1810-1815.

21. Smith WS, Lev MH, English JD, Camargo EC, Chou M, Johnston SC, et al. Significance of large vessel intracranial occlusion causing acute ischemic stroke and TIA. Stroke 2009;40:38343840 .

22. Nam HS, Kim EY, Kim SH, Kim YD, Kim J, Lee HS, et al. Prediction of thrombus resolution after intravenous thrombolysis assessed by CT-based thrombus imaging. Thromb Haemost 2012;107:786-794.

23. Parsons MW, Christensen S, McElduff P, Levi CR, Butcher KS, De Silva DA, et al. Pretreatment diffusion- and perfusion-mr lesion volumes have a crucial influence on clinical response to stroke thrombolysis. J Cereb Blood Flow Metab 2010;30:
1214-1225.

24. Yoo AJ, Verduzco LA, Schaefer PW, Hirsch JA, Rabinov JD, González RG. MRI-based selection for intra-arterial stroke therapy: value of pretreatment diffusion-weighted imaging lesion volume in selecting patients with acute stroke who will benefit from early recanalization. Stroke 2009;40:2046-2054.

25. Ogata T, Christensen S, Nagakane Y, Ma H, Campbell BC, Churilov L, et al. The effects of alteplase 3 to 6 hours after stroke in the EPITHET-DEFUSE combined dataset: post hoc case-control study. Stroke 2013;44:87-93. Epub 2012 Dec 18.

26. Ford GA, Ahmed N, Azevedo E, Grond M, Larrue V, Lindsberg PJ, et al. Intravenous alteplase for stroke in those older than 80 years old. Stroke 2010;41:2568-2574.

27. IST-3 collaborative group, Sandercock P, Wardlaw JM, Lindley RI, Dennis M, Cohen G,et al. The benefits and harms of intravenous thrombolysis with recombinant tissue plasminogen activator within $6 \mathrm{~h}$ of acute ischaemic stroke (the third international stroke trial [IST-3]): a randomised controlled trial. Lancet 2012;379:2352-2363. Epub 2012 May 23.

28. Assessment of the Safety and Efficacy of a New Thrombolytic (ASSENT-2) Investigators, Van De Werf F, Adgey J, Ardissino D, Armstrong PW, Aylward P, et al. Single-bolus tenecteplase compared with front-loaded alteplase in acute myocardial infarction: the ASSENT-2 double-blind randomised trial. Lancet 1999;354:716-722.

29. Al-Shwafi KA, de Meester A, Pirenne B, Col JJ. Comparative fibrinolytic activity of front-loaded alteplase and the single-bolus mutants tenecteplase and lanoteplase during treatment of acute myocardial infarction. Am Heart J 2003;145: 217-225.

30. Haley EC Jr, Thompson JL, Grotta JC, Lyden PD, Hemmen TG, Brown DL, et al. Phase IIB/III trial of tenecteplase in acute ischemic stroke: results of a prematurely terminated randomized clinical trial. Stroke 2010;41:707-711.

31. Parsons MW, Miteff F, Bateman GA, Spratt N, Loiselle A, Attia $\mathrm{J}$, et al. Acute ischemic stroke: imaging-guided tenecteplase treatment in an extended time window. Neurology 2009;72: 915-921.

32. Parsons M, Spratt N, Bivard A, Campbell B, Chung K, Miteff F, et al. A randomized trial of tenecteplase and alteplase for acute ischemic stroke. N Engl J Med 2012;366:1099-1107.

33. Hawkey C. Inhibitor of platelet aggregation present in saliva of the vampire bat Desmodus rotundus. Br J Haematol 1967;13: 1014-1020.

34. Schleuning WD. Vampire bat plasminogen activator DSPA-alpha-1 (desmoteplase): a thrombolytic drug optimized by natural selection. Haemostasis 2001;31:118-122.

35. Bringmann P, Gruber D, Liese A, Toschi L, Kratzchmar J, Schleuning WD, et al. Structural features mediating fibrin se- 
lectivity of vampire bat plasminogen activators. J Biol Chem 1995;270:25596-25603.

36. Hacke W, Albers G, Al-Rawi Y, Bogousslavsky J, Davalos A, Eliasziw M, et al. The Desmoteplase in Acute Ischemic Stroke Trial (DIAS): a phase II MRI-based 9-hour window acute stroke thrombolysis trial with intravenous desmoteplase. Stroke 2005;36:66-73.

37. Lees KR, Bluhmki E, von Kummer R, Brott TG, Toni D, Grotta JC, et al. Time to treatment with intravenous alteplase and outcome in stroke: an updated pooled analysis of ECASS, ATLANTIS, NINDS, and EPITHET trials. Lancet 2010;375: 1695-1703.

38. del Zoppo GJ, Poeck K, Pessin MS, Wolpert SM, Furlan AJ, Ferbert A, et al. Recombinant tissue plasminogen activator in acute thrombotic and embolic stroke. Ann Neurol 1992;32: 78-86.

39. Alexandrov AV, Grotta JC. Arterial reocclusion in stroke patients treated with intravenous tissue plasminogen activator. Neurology 2002;59:862-867.

40. Tomsick T, Broderick J, Carrozella J, Khatri P, Hill M, Palesch $\mathrm{Y}$, et al. Revascularization results in the Interventional Management of Stroke II trial. AJNR Am J Neuroradiol 2008;29:582587.

41. Broderick JP, Palesch YY, Demchuk AM, Yeatts SD, Khatri P, Hill MD, et al. Endovascular therapy after intravenous t-Pa versus t-PA alone for stroke. N Engl J Med 2013;368:893-903.

42. Kidwell CS, Jahan R, Gornbein J, Alger JR, Nenov V, Ajani Z, et al. A trial of imaging selection and endovascular treatment for ischemic stroke. N Engl J Med 2013;368:914-923.

43. Saver JL, Jahan R, Levy EI, Jovin TG, Baxter B, Nogueira RG, et al. Solitaire flow restoration device versus the Merci Retriever in patients with acute ischaemic stroke (SWIFT): a randomised, parallel-group, non-inferiority trial. Lancet 2012; 380:1241-1249.

44. Nogueira RG, Lutsep HL, Gupta R, Jovin TG, Albers GW, Walker GA, et al. Trevo versus Merci retrievers for thrombectomy revascularisation of large vessel occlusions in acute ischaemic stroke (TREVO 2): a randomised trial. Lancet 2012; 380:1231-1240.

45. Cintas P, Nguyen F, Boneu B, Larrue V. Enhancement of enzymatic fibrinolysis with $2-\mathrm{MHz}$ ultrasound and microbubbles. J
Thromb Haemost 2004;2:1163-1166.

46. Everbach EC, Francis CW. Cavitational mechanisms in ultrasound-accelerated thrombolysis at $1 \mathrm{MHz}$. Ultrasound Med Biol 2000;26:1153-1160.

47. Eggers J, König I, Koch B, Händler G, Seidel G. Sonothrombolysis with transcranial color-coded sonography and recombinant tissue-type plasminogen activator in acute middle cerebral artery main stem occlusion: results from a randomized study. Stroke 2008;39:1470-1475.

48. Cintas P, Le Traon AP, Larrue V. Enhancement of enzymatic fibrinolysis with $2-\mathrm{MHz}$ ultrasound and microbubbles. J Thromb Haemost 2004;2:1163-1166.

49. Eisenberg PR, Sobel BE, Jaffe AS. Activation of prothrombin accompanying thrombolysis with recombinant tissue-type plasminogen activator. J Am Coll Cardiol 1992;19:1065-1069.

50. De Luca G, Suryapranata H, Stone GW, Antoniucci D, Tcheng JE, Neumann FJ, et al. Abciximab as adjunctive therapy to reperfusion in acute ST-segment elevation myocardial infarction: a meta-analysis of randomized trials. JAMA 2005;293:17591765.

51. Seitz RJ, Meisel S, Moll M, Wittsack HJ, Junghans U, Siebler M. The effect of combined thrombolysis with rtPA and tirofiban on ischemic brain lesions. Neurology 2004;62:2110-2112.

52. Morris DC, Silver B, Mitsias P, Lewandowski C, Patel S, Daley $S$, et al. Treatment of acute ischemic stroke with recombinant tissue plasminogen activator and abciximab. Acad Emerg Med 2003;10:1396-1399.

53. Korin N, Kanapathipillai M, Matthews BD, Crescente M, Brill A, Mammoto T, et al. Shear-activated nanotherapeutics for drug targeting to obstructed blood vessels. Science 2012;337: 738-742.

54. Bivard A, Spratt N, Levi C, Parsons M. Perfusion computer tomography: Imaging and clinical validation in acute ischaemic stroke. Brain 2011;134:3408-3416.

55. Colman R, Marder V, Clowes A, George J, Goldhaber S. Hemostasis and Thrombosis: Basic Principles and Clinical Practice. 3rd ed. Philadeplhia: J. B. Lippincott Company, 1994;3.

56. Nordt TK, Bode C. Thrombolysis: newer thrombolytic agents and their role in clinical medicine. Heart 2003;89:1358-1362.

57. Baruah DB, Dash RN, Chaudhari MR, Kad-am SS. Plasminogen activators: a comparison. Vascul Pharmacol 2006; 44:1-9. 